\title{
Human trials go-ahead for the AIDS vaccine with a difference
}

\section{London}

A prototy A AIDS vaccine that has been awaiting approval in the United States for a year has received the go-ahead in Great Britain. A small-scale trial of the toxicity and immunogenicity of the vaccine, a synthetic peptide, will begin this summer at St Stephen's Hospital in Fulham.

The 30-amino-acid peptide, known as HGP-30, represents a small part of the gpl7 protein of human immunodeficiency virus 1 (HIV-I), the cause of AIDS. Since peptides are not on their own very immunogenic, the HGP-30 has been linked to a carrier, keyhole limpet haemocyanin, and will be given together with alum as an adjuvant.

Initial tests, which are expected to involve 24 volunteers, will examine potential side effects and the extent to which the preparation induces antibodies that will neutralize HIV-1. Tests on animals, including rodents, rhesus monkeys and two chimpanzees, have already demonstrated the safety and immunogenicity of the preparation.

The tests will be carried out by Dr Brian Gazzard, with the approval of the Riverside Health Authority and provisional approval of the Clinical Trial Section of the Department of Health and Social Security. Viral Technologies Inc., a Californian joint venture of the CEL-SCI Corporation and Alpha 1 Biomedicals, will supply the HGP-30 preparation.

HGP-30 represents amino acids 86-115

of the p17 protein, with one amino acid difference. While, unlike the envelope protein on which most candidate vaccines are based, p17 is not generally considered to be on the suface of HIV-1, infected patients nonetheless produce antibodies to it. Recent evidence suggests that in many patients the disappearance of antibodies to p17 is a prelude to the development of AIDS. So a vaccine that induces such antibodies may help prevent progression. Therefore it is likely to be tested first in those who are already infected with HIV-1.

Much of the work that led to the trial has been carried out by a team led by Professor Allan Goldstein of The George Washington School of Medicine and Health Sciences in Washington D.C. together with Dr Prem Sarin and colleagues at the National Cancer Institute in Bethesda.

Earlier this week, Goldstein expressed some frustration at the lack of decision by the Food and Drug Administration, which has been considering an application for a trial of HGP-30 at the George Washington University for a year. He was delighted, however, that the UK trial is to begin and hopeful that applications in other countries will also receive approval.

Other trials under way include that of a killed HIV (see Nature 332, 668; 1988), a recombinant vaccinia virus that produces the gp160 envelope protein of HIV (see Nature 332, 728; 1988), and purified gp160 itself.

Peter Newmark

\section{Lenin prizes reflect centralized Soviet science}

\section{London}

THE Lenin prizes for Science were announced on 22 April, the anniversary of Lenin's birth. This year, nine prizes were awarded, in line with the revised procedures introduced under the perestroika reforms, which reduce the number of prizes and makes the selection procecure more rigorous. Of these, seven were given for fundamental research (three for physics, one for geophysics, one for neuroscience and one for linguistics) and only three for work with obvious practical applications - the synthesis of carbohydrates, automatic control and a pipe contact-welding process.

Only one prize (for the welding process) is shared between academics and industry, and seven out of the nine prizes go to scientists from the European part of the Soviet Union. Only one prize, for tectonics, went to the far-eastern branch of the Academy of Sciences. And seven out of the nine prizes went, wholly or partly, to academicians or staff of the Academy of Sciences of the USSR, while the remaining two went to the
Georgian and (in part) the Ukrainian Academies. Soviet science, the prizes suggest, is still heavily dependent on the old, traditional centres and structutes.

A very different impression, however, emerges from the celebratory articles for "Scientists' Day", the third Sunday in April. These commend, not the long "cycles" of work which gain the Lenin prizes, but the recent advances in superconductivity and the new cryogenic aviation fuel. They stress the outlying science centres, the far eastern and Ural branches of the Academy, where science in the words of Pravda "is coming of age". The contributions of researchers in higher-education colleges and industrial institutes stress the need for closer links between science and production, and the need for science to conform to the new principles of costefficiency. In short, a summary of $\mathrm{Mr}$ Gorbachev's vision of Soviet science. But, the Lenin prizes suggest, this is not yet where the honours are to be won.

Vera Rich
No rare earths in new film

Tokyo

THE speed of research on the new rareearth-free superconductors is breathtaking. It is barely a month since Tohoku University researchers announced a chemical vapour deposition technique for making thin films of yttrium-barium-copper oxide (Nature 332, 295; 1988), but Fujitsu Ltd already claims to have used a similar technique to deposit an epitaxial monocrystalline thin film of bismuth-strontium-calcium-copper oxide on a large-area substrate. The technique has potential in the mass production of high-criticaltemperature superconducting epitaxial wafers and electronic devices.

Chemical vapour deposition is a cheap and versatile technique widely used in the semiconductor industry for production of thin films, but it is only recently that Japanese researchers have adapted the technique to high-temperature superconductors.

In Fujitsu's method, halides of bismuth, copper, calcium and strontium are heated in a quartz vessel under a gradient of temperatures from $200^{\circ} \mathrm{C}$ for $\mathrm{BiCl}_{3}$ at the downstream end of the vessel to $825^{\circ} \mathrm{C}$ for $\mathrm{SrI}_{2}$ at the upstream end (see diagram on page 767). Inert helium carries the vaporized halides towards the substrate $(\mathrm{MgO})$, where chemical reactions occur in an atmosphere of oxygen, helium and water vapour, and a superconducting thin film is deposited on the substrate. No annealing at high temperature is required.

Using the technique, Fujitsu claims to have coated a $30 \times 30 \mathrm{~mm}$ basal crystal plane (001) of $\mathrm{MgO}$ with an epitaxial monocrystalline film of bismuth-strontium-calcium-copper oxide. The film is 0.3 micrometres thick, was deposited in about half an hour, and has a critical temperature, at which electrical resistance drops to zero, of $78 \mathrm{~K}$.

This is the first convincing report of a monocrystalline thin film of the new rareearth-free superconductors. Initially Fujitsu plans to develop the technique to deposit films on six-inch silicon wafers. And in the short term, the company foresees application of the technique to the production of a superconducting quantum interference device (SQUID) for measuring minute magnetic fields.

In the long term, development of multilayer deposition may allow manufacture of tunnelling-type Josephson devices, superconducting transistors and large-scale integrated circuits with superconducting wiring. But Fujitsu still has a long way to go - the critical current density of the thin film has not yet been determined, according to a company spokesman.

David Swinbanks 